\title{
Prophylactic Atropine administration should be considered during laparoscopic surgery
}

Maharjan SK' ${ }^{1}$, Tabdar $\mathbf{S}^{2}$

'Shyam Krishna Maharjan, Associate Professor, ${ }^{2}$ Sushila Tabdar, Assistant Professor

Department of Anaesthesiology and Intensive Care,

Kathmandu Medical College Teaching Hospital, Kathmandu, Nepal

\section{Abstract}

Background: Routine use of vagotonic drugs during general anaesthesia with mechanical ventilation and carboperitoneum creation during laparoscopic surgery may lead to severe bradycardia and even asystole, which can be countered by prophylactic use of Atropine sulphate.

Objective: To study whether Atropine sulphate administered one minute after endotracheal intubation will be effective in preventing bradycardia induced by vagotonic anaesthetics and carboperitoneum during laparoscopic surgery.

Methods: Ninety two patients of American Society of Anaesthesiologist Physical Status I were included in the study. These patients were randomly divided into two groups (Control group and Atropine group) of 46 each by envelope method. Control group received one $\mathrm{mL}$ of saline and Atropine group received $0.6 \mathrm{mg}$ (one $\mathrm{mL}$ ) Atropine one minute after endotracheal intubation. Heart rate, systolic, diastolic and mean arterial pressures were monitored before intubation; one, three and five minutes after intubation; five, 15 and 30 minutes after carboperitoneum creation and before and after extubation. Atropine $0.6 \mathrm{mg}$ was given intravenously if any of patients developed heart rate less than 50 beats per minute.

Results: Demographic characteristics were similar in both groups. Thirty percent (14 out of 46) of patients in control group developed bradycardia immediately after carboperitoneum creation and no patients developed bradycardia in atropine group. Haemodynamic parameters after intubation, during intraoperative period and after extubation were similar in both groups.

Conclusion: Vagolytic drug (Atropine sulphate) should be considered if vagotonic anaesthetic drugs are used along with carboperitoneum creation during laparoscopic surgery.

Key words: Atropine, Bradycardia, Carboperitoneum, Laparoscopy

\section{INTRODUCTION}

$\mathrm{D}^{2}$ uring general anaesthesia, drugs are used for analgesia, amnesia and muscle relaxation. Initially used drugs like Pethidine, Sodium thiopentone and Pancuronium were vagolytic and there was no bradycardia and hypotension following use of these drugs. The newer drugs like Fentanyl, Propofol and Vecuronium which are being used extensively during general anaesthesia are vagotonic and can cause severe bradycardia and even asystole during carboperitoneum creation for laparoscopic surgery ${ }^{1,2}$.

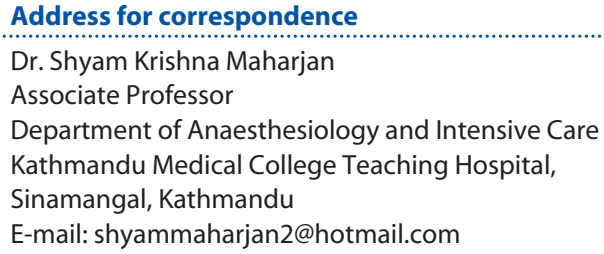

The vagotonic effect of these drugs will be aggravated by peritoneal insufflations of carbon dioxide (carboperitoneum) and manipulation of viscera as well. Reflex cardiovascular depression caused by anaesthetics and surgical procedures due to vasodilatation and bradycardia is termed vasovagal syncope (neurogenic syncope) or Bejold Zaris reflex. There is sympathetic inhibition and parasympathetic activation (vagal stimulation or vagotonic effect) leading to severe cardiovascular depressant effects ${ }^{3}$.

During general anaesthesia, heart rate alteration suggests change in depth of anaesthesia, vagal overactivity, hypercarbia and effects of drugs. Simple vagal responses will be abolished with stoppage of stimulus but those due to strong vagotonic drugs and carboperitoneum creation may lead to life threatening bradycardia and in rare instances asystolic cardiac 
arrest and cardiovascular collapse. Anticholinergic drugs (Atropine sulphate and Glycopyrrolate) prevent bradycardia due to parasympathetic over activity (due to drugs and carboperitoneum creation) by blocking the parasympathetic muscarinic receptors ${ }^{4}$.

The cardiovascular effects are mediated by afferent fibres from heart, from baroreceptors and even compression of inferior venacava as in pregnancy and carboperitoneum creation during laparoscopy. Ephedrine is the drug of choice to counter both vasodilatation and bradycardia but in laparoscopy with use of vagotonic drugs, the response is extensive and vagolytic drug is necessary to counter the effects and epinephrine may be the choice if there is asystole $e^{5,6}$.

Intraoperative bradycardia is very common with use of newer anaesthetic drugs and aggravated by carboperitoneum creation during laparoscopic surgery. Prophylactic administration of Atropine sulphate (one minute after endotracheal intubation) was carried out in this study to observe the efficacy of drug in prevention of bradycardia during laparoscopic surgery.

\section{METHODS}

This is a prospective, randomised double blind study done at Kathmandu Medical College Teaching Hospital, a tertiary care hospital, during three months period from 2012 January first to March 31, in patients undergoing laparoscopic surgery after getting ethical clearance from the ethical committee of the institute. Ninety two patients of age 18 to 65 years of both gender and American Society of Anesthesiologist's Physical Status classification (ASA PS) I were included. They were randomly divided into two groups of 46 each, control group and Atropine group by envelope method.

Premedication was avoided to minimise any untoward effects on the study as most of the drugs have effects on heart rate and there is no potential harm on patients of not using premedication drugs as all patients were of ASA I physical status. American Society of Anaesthesiologist (ASA) standard monitors were used and baseline heart rate, systolic, diastolic and mean arterial pressure were recorded. Standard general anaesthesia was made (Fentanyl $2.0 \mu \mathrm{g} / \mathrm{kg}$, Propofol $2.0 \mathrm{mg} / \mathrm{kg}$ and Vecuronium $0.1 \mathrm{mg} / \mathrm{kg}$ ). Airway was managed with tracheal intubation and anaesthesia maintained with $1-2 \%$ Isoflurane with $50 \%$ oxygen in air.

Control group of patients were given one $\mathrm{mL}$ of saline and Atropine group were given $0.6 \mathrm{mg}$ (one $\mathrm{mL}$ ) Atropine sulphate one minute after tracheal intubation to minimize effect of Atropine on cardiovascular system during laryngoscopy and tracheal intubation. Test drug was given by the anaesthesiologist who was not involved in data collection and patients were also not aware of the test drug used. Heart rate, systolic, diastolic and mean arterial pressure was monitored one, three and five minutes after intubation; one, three, five, 15 and 30 minutes after carboperitoneum creation and before and after extubation. One litre of lactated ringer's solution was used during intraoperative period in all patients.

Sample size calculation was based on previous study of average heart rate increment of 30 per minute with control when atropine $0.6 \mathrm{mg}$ was used, alpha level of 0.05 and power of $80 \%$, minimum 20 patients in each group is necessary for comparison of group means and for $t$ test ${ }^{4}$. Statistical analysis was done using SPSS 17 for Windows and data were reported as mean (standard deviation). Intergroup comparison was made using independent samples t test (Levene's test for equality of variances) and $p$ value less than 0.05 was taken as statistically significant difference between the groups.

\section{RESULTS}

The demographic variables (age, gender, weight and height) were similar in two groups. The duration of anaesthesia and surgery were also comparable, Table 1.

When intraoperative heart rate was analysed before induction (basal), after induction and after intubation, there was similar minimal increment in heart rate in both groups because of laryngoscopy and tracheal intubation. The heart rate in control group gradually decreased from after intubation level to significant bradycardia, 90.02 (11.49) per minute to 53.38 (15.11) per minute, $p$ value: 0.020 . Fourteen patients out of 46 (30\%) developed bradycardia (heart rate less than 50 per minute) requiring Atropine administration, three of them required $1.2 \mathrm{mg}$ and rest $0.6 \mathrm{mg}$ to bring heart rate more than 60 per minute. There was no significant differences in heart rate between two groups in basal, before intubation, one three and five minutes after intubation; one three, five fifteen and thirty minutes after carboperitoneum; before and after extubation as well $(p$ value $>0.05)$.

Systolic blood pressure was also in lower range during bradycardia compared to study group but there was no significant differences at any time of study period, table 2 .

The patients who received $0.6 \mathrm{mg}$ Atropine one minute after tracheal intubation, were stable and maximum heart rate was 105.89 (8.82) per minute from after 
intubation level of $85.44(15.11)$ per minute. Maximum heart rate during intraoperative period was not more than 120 per minute and systolic blood pressure was also within normal range. Diastolic and mean arterial pressure was maintained within normal limit in both groups, table 2. The recorded hemodynamics on individual time intervals mentioned in methods is shown in line diagrams number one and two below.

Heart rate (basal, before intubation, after intubation and three, five, fifteen and thirty minutes after carboperitoneun creationand before and after extubation) was statistically not significant. Similarly, systolic, diastolic and mean arterial pressure between two groups was statistically not significant in basal, before intubation, one, three and five minutes after intubation and one, three, five, fifteen and thirty minutes after carboperitoneum and before and after extubation. The minimum heart rate recorded in atropine group during maximal vagal stimulation that is after one minute of carboperitoneum was 60 per minute where as in control group the minimum heart rate recorded was 30 per minute before atropine administration.

No patients needed epinephrine to counter the bradycardia; three patients needed $1.2 \mathrm{mg}$ of atropine sulphate to counter the extreme vagal stimulation. The heart rate in control group, even after use of atropine sulphate during the intraoperative period was less than that of study group suggesting the strong vagal stimulation during carboperitoneum creation and viscera manipulation (Table 2).

Haemodynamic variables were within acceptable range and almost similar in two groups before and after intubation; during intraoperative period (except one minute after carboperitoneum) and extubation as well, $\mathrm{p}$ value more than 0.05 in all mentioned period (table 2 ).

Table 1: Demographic variables, duration of anaesthesia and surgery, mean (standard deviation).

\begin{tabular}{lccc}
\hline Variables & Control group & Atropine group & p value \\
\hline Age, years & $49.93(14.41)$ & $45.48(15.80)$ & 0.363 \\
\hline Gender, F:M* & $36: 9$ & $39: 6$ & 0.949 \\
Weight, kg & $57.28(10.64)$ & $57.16(8.80)$ & 0.352 \\
Height, feet & $4.94(0.45)$ & $5.08(0.49)$ & 0.957 \\
Duration of anaesthesia, minutes & $51.60(16.10)$ & $59.17(15.64)$ & 0.444 \\
\hline Duration of surgery, minutes & $42.44(14.46)$ & $50.17(15.07)$ & 0.943 \\
\hline
\end{tabular}

*Female:Male

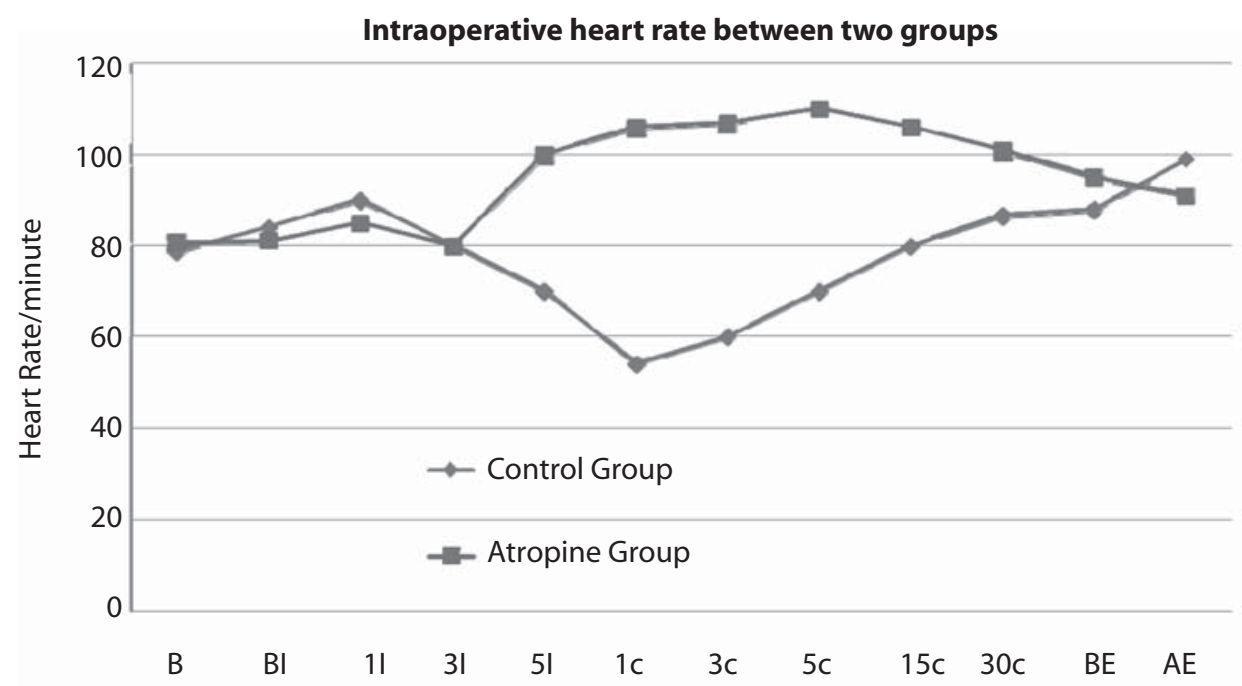

Figure 1: Line diagram showing intraoperative heart rate between two groups in different times of study.

B: basal, BI: before intubation, 1I: one minute after intubation; 31, 5l: three and five minutes after intubation. 1c: one minute after carboperitoneum; 3c, 5c, 15c, 30c: three, five, fifteen and 30 minutes after carboperitoneum. BE: before extubation, AE: after extubation. 


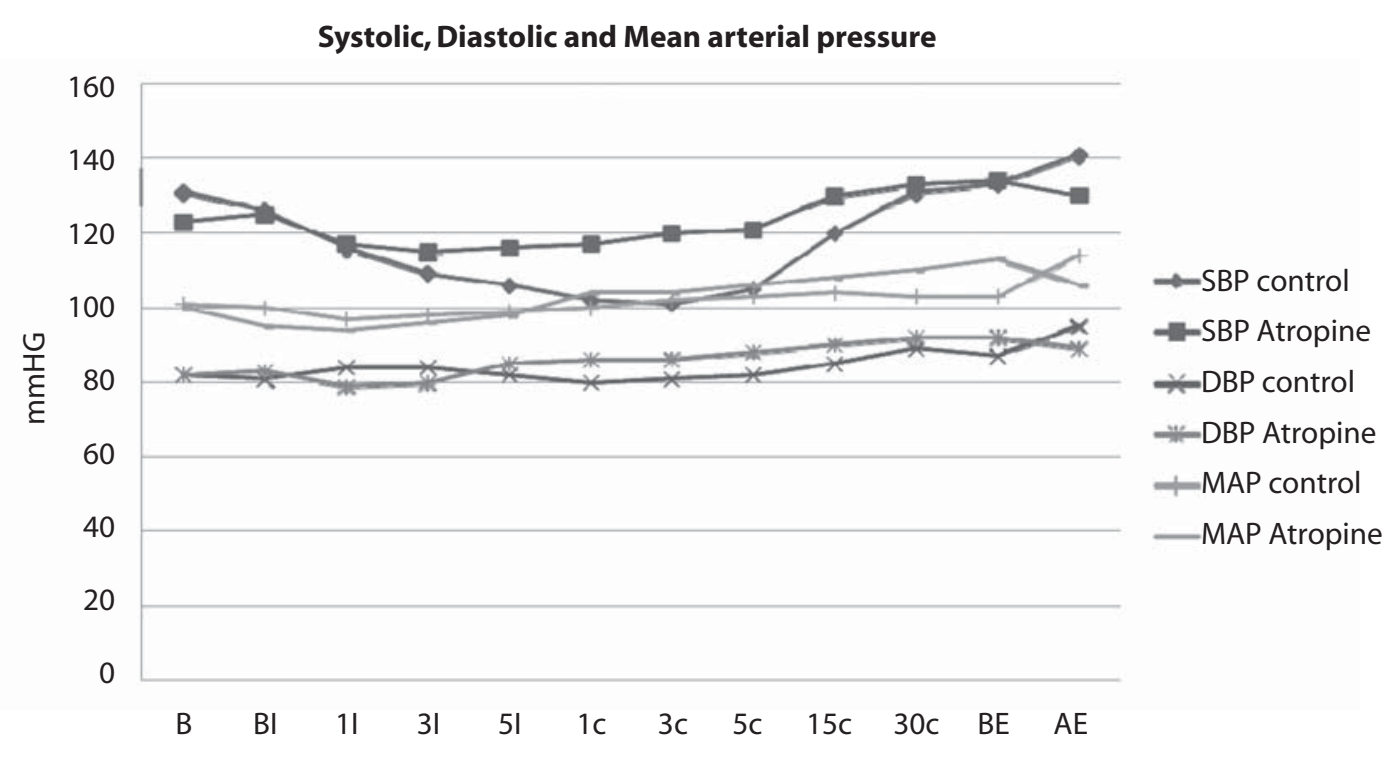

Figure 2: Line diagram showing comparison of systolic, diastolic and mean arterial pressure between two groups in different times of study.

B: basal, Bl: before intubation, 1l: one minute after intubation; 31, 5l: three and five minutes after intubation. 1c: one minute after carboperitoneum; 3c, 5c, 15c, 30c: three, five, fifteen and 30 minutes after carboperitoneum. BE: before extubation, AE: after extubation.

Table 2: Heart rates, systolic, diastolic and mean arterial pressure in studied groups, mean (standard deviation)

\begin{tabular}{|c|c|c|c|c|c|c|c|}
\hline Variables & Basal & $\begin{array}{c}\text { Before } \\
\text { intubation }\end{array}$ & $\begin{array}{l}1 \text { minute } \\
\text { after } \\
\text { intubation }\end{array}$ & $\begin{array}{c}1 \text { minute after } \\
\text { carboperitoneum }\end{array}$ & $\begin{array}{c}\text { During } \\
\text { carboperitoneum }\end{array}$ & $\begin{array}{c}\text { Before } \\
\text { extubation }\end{array}$ & $\begin{array}{c}\text { After } \\
\text { extubation }\end{array}$ \\
\hline \multicolumn{8}{|l|}{$\mathrm{HR}^{*}\left(\min ^{-1}\right)$} \\
\hline Control & $78.86(12.74)$ & $84.97(13.33)$ & 90.02 (11.49) & $53.38(15.11)$ & 86.77 (12.98) & $88.27(17.01)$ & 98.52 (17.38) \\
\hline Atropine & $80.65(14.11)$ & $81.19(16.74)$ & $85.44(15.11)$ & $105.89(8.82)$ & 100.85 (10.92) & 94.74 (16.70) & 91.21 (15.77) \\
\hline$p$ value & 0.502 & 0.143 & 0.088 & 0.020 & 0.107 & 0.788 & 0.336 \\
\hline \multicolumn{8}{|l|}{$\begin{array}{l}\mathrm{SBP}^{\dagger} \\
(\mathrm{mmHg})\end{array}$} \\
\hline Control & $130.2(17.12$ & $126.7(23.6)$ & $116.5(16.8)$ & $101.2(10.4)$ & $131.5(20.6)$ & $133.3(20.7)$ & $141.9(21.3)$ \\
\hline Atropine & $122.9(16.9)$ & $125.5(19.7)$ & $116.7(18.4)$ & $117.2(13.6)$ & $133.0(20.9)$ & $134.6(18.5)$ & $130.0(21.0)$ \\
\hline$p$ value & 0.700 & 0.320 & 0.341 & 0.316 & 0.697 & 0.953 & 0.912 \\
\hline \multicolumn{8}{|l|}{$\begin{array}{l}\mathrm{DBP}^{\ddagger} \\
(\mathrm{mmHg})\end{array}$} \\
\hline control & $82.6(12.5)$ & $81.4(14.5)$ & $84.0(18.8)$ & $80.3(11.6)$ & $89.2(14.1)$ & $87.4(14.8)$ & 95.8 (15.7) \\
\hline atropine & $82.8(12.3)$ & $82.0(13.2)$ & $79.1(16.1)$ & $86.0(17.36)$ & $92.7(17.0)$ & $92.0(14.4)$ & 88.9 (13.7) \\
\hline$p$ value & 0.865 & 0.620 & 0.171 & 0.054 & 0.372 & 0.989 & 0.349 \\
\hline \multicolumn{8}{|l|}{$\begin{array}{l}\text { MAP§ } \\
(\mathrm{mmHg})\end{array}$} \\
\hline Control & $101.1(18.2)$ & $100.9(16.5)$ & $97.4(24.5)$ & $100.5(14.8)$ & $103.0(18.1)$ & $103.5(21.3)$ & $114.7(20.4)$ \\
\hline Atropine & $99.8(19.3)$ & $94.8(16.6)$ & $94.3(20.3)$ & $104.8(17.2)$ & $110.0(17.7)$ & $113.0(19.6)$ & $106.4(15.3)$ \\
\hline$p$ value & 0.864 & 0.614 & 0.195 & 0.343 & 0.437 & 0.804 & 0.142 \\
\hline
\end{tabular}

*HR: Heart rate; ${ }^{\dagger}$ Systolic BP; ${ }^{*}$ Diastolic BP; ${ }^{\S}$ Mean arterial pressure 


\section{DISCUSSION}

This is a comparative study of two groups of patients with and without Atropine sulphate administration during laparoscopic surgery with vagotonic anaesthetic drugs for induction and maintenance of anaesthesia. This study revealed that use of Atropine sulphate after intubation prevents bradycardia after carboperitoneum creation during laparoscopic surgery. In this study Atropine sulphate was given one minute after endotracheal intubation to avoid additive effect on stress response due to laryngoscopy and airway manipulation.

Various studies have reported bradycardia and even asystole after use of newer induction agents especially Propofol, Vecuronium and Fentanyl ${ }^{2,7,8}$, but in our study bradycardia was not encountered after use of these drugs (before carboperitoneum creation) probably that was countered by catecholamine surge after airway manipulation. Bradycardia in fourteen patients (30\%) presented for laparoscopic surgery after carboperitoneum creation along with use of vagotonic drugs is alarming and careful haemodynamic monitoring and prophylactic management with Atropine sulphate should be considered to minimize morbidities. There was no significant tachycardia and hypertension after use of $0.6 \mathrm{mg}$ of Atropine sulphate as all patients were of ASA PS I class.

Doyle DJ reported that reflex bradycardia and sinus arrest may occur in any sort of surgical procedures, neurosurgery to intraabdominal, ophthalmic and simple liver biopsies as well and premedication with an anticholinergic agent may be a suitable preventive measure ${ }^{6}$. Yorozu l et al reported that common causes of bradycardia during general anaesthesia are drugs like Propofol, Vecuronium, newer synthetic opioids, pneumoperitoneum creation and vagal stimulation and Atropine premedication keeps the heart rate in high normal side in whole perioperative period'. In present study also Atropine administered patients had heart rate of 105.89 (8.82) per minute and there was no evidence of bradycardia.

Kinsella SM et al in their extensive study, concluded that reflex cardiovascular depression with bradycardia during anaesthesia may be life threatening and must be monitored carefully and early recognition and treatment with Atropine sulphate and Epinephrine must be used early in established cardiac arrest if any occur during regional and general anaesthesia ${ }^{3}$. Homayun $A$ et al suggested that routine prophylactic use of anticholinergic agent might be helpful in prevention of sinus bradycardia during urological laparoscopic surgery. Significant bradycardia was seen in $28.1 \%$ of patients and none had bradycardia when Atropine premedication was used ${ }^{4}$. This result is almost similar with our result in incidence of bradycardia and prevention during laparoscopic surgery.

Myles PS analysed heart rate changes during laparoscopic gynaecological surgeries and reported that $47 \%$ patients had arrhythmias among them 30\% had bradycardia, all episodes occurring during carbon dioxide insufflations and/or traction on pelvic tissues ${ }^{5}$. The results of this study are almost similar to our results, $30 \%$ incidence of bradycardia and occurring during carbon dioxide insufflations.

Tramer MR et al made a systemic search for any report that Propofol increases the risk of bradycardia, asystole and death from bradicardic events. Almost $24 \%$ patients developed bradycardia with Propofol induction and one of 660 patients had asystole. The risk of bradycardia related death during Propofol anaesthesia was estimated to be 1.4 in 100,000². The bradycardic events are almost near to our result but sample size of our study was comparatively smaller. The result showed that the bradycardia and consequences of that were more in patients with Propofol combined with Fentanyl and Vecuronium, same as in our result.

Maruyama $\mathrm{K}$ et al used $0.5 \mathrm{mg}$ Atropine sulphate prophylactically to assess bradycardia and hypotension during Propofol, Vecuronium and Ramifentanyl anaesthesia and found that Atropine sulphate could prevent bradycardia but not hypotension during that combination anaesthesia ${ }^{7}$. Takashi $\mathrm{H}$ et al reported that Propofol induced bradycardia is difficult to treat with higher doses of Atropine as well 8 . In our study, almost same anaesthetics were used and one third of them developed bradycardia which was corrected by use of Atropine sulphate and some needed even $1.2 \mathrm{mg}$ of Atropine sulphate.

Marlene DV et al reported two cases of asystolic cardiac arrest during traction on gall bladder for cholecystectomy ${ }^{9}$ and Clayton D described sudden bradycardia progressing to asystole before Atropine was administered in patients undergoing gynaecological laparoscopic surgery ${ }^{6}$. Hoda et al reported asystolic cardiac arrest during balloon insufflations for endoscopic extraperitoneal radical prostatectomy in three patients ${ }^{10}$. During our study there was no cardiac arrest but severe bradycardia up to 30 per minute was recorded and successfully treated with Atropine sulphate. 
Our study did not reveal bradycardia related to induction of Propofol and other vagotonic drugs, exact per kilogram dose of Atropine sulphate to counter the bradycardia and postoperative effects of Atropine sulphate administration. As this study was done in ASA physical status I patients only and $0.6 \mathrm{mg}$ of Atropine administration might be deleterious to patients with hypertension and hyperdynamic circulation.

\section{REFERENCES}

1. Yoroju I, Lijima T, Matsumoto M, Yeo X, Takaji T. Factors influencing intra-operative bradycardia in adult patients. J Anesth. 2007;21(2):136-41.

2. Tramer MR, Moore RA, MCQuay HJ. Propofol and bradycardia: causation, frequency and severity. BJA.1997;78:642-51.

3. Kinsella SM, Tuckey JP. Perioperative bradycardia and asystole: relationship to vasovagal syncope and the Bezold Jarish Reflex. BJA. 2001;86:859-68.

4. Homayun A, Sadrollah M, Farmarz MAB. Prevention of bradycardia by Atropine sulphate during urological laparoscopic surgery. Urol J. 2009;6:92-5.

5. Myles PS. Bradi-arrhythmia and laparoscopy: a prospective study of heart rate changes with laparoscopy. Aust NZ J Obstet Gynecol. 1991;31:1713.

\section{CONCLUSION}

Atropine sulphate administration should be considered when vagotonic drugs are used during induction and maintenance of anaesthesia along with carboperitoneum creation for laparoscopic surgery in ASA PS class I patients with crucial monitoring to minimize bradycardia and subsequent aftermaths of strong parasympathetic effects.
6. Doyle DJ. Reflex bradycardia during surgery. Can J Anesth. 1990;37(2):210-22.

7. Maruyam K, Nishikawa Y, Nakagawa H, Ariyama J, Kitamura A, Hayashida M. Can intravenous Atropine prevent bradycardia and hypotension during induction of total intravenous anaesthesia with Propofol and Remifentanil? J Anesth.2010;24(2):293.

8. Takashi $\mathrm{H}$, Toshiaki $\mathrm{N}$. Heart rate response to intravenous Atropine during Propofol anaesthesia. Anaesth Analg.1995;2:389.

9. Marlene DV, Nirman T, Carey D. Recurrent asystolic cardiac arrest and laparoscopic cholecystectomy: a case report and review of literature. JSLS. 2004 JanMar;8(1):65-8.

10. Hoda MR, Freidrichs M, Christoph K, Thomas N, Gralf P. Asystolic cardiac arrest during balloon insufflation for endoscopic extraperitoneal radical prostatectomy. J Endourol. 2009 Feb;23(2):329-2. 